\title{
Financial Prospect to The Application of High Rate Water Treatment Plant System
}

\author{
Mohajit \\ Institute of Technology Bandung - Indonesia \\ email:mohajito@hotmail.com
}

\begin{abstract}
The High Rate Water Treatment Plant (HR-WTP) system, which is inexpensive, effective and efficient, has been developed to reduce the common operational problems, and also as an alternative for the development of water treatment plant systems capacity in Indonesia. Implementation of HR-WTP system in up-rating of the Dekeng-WTP system at PDAM Kota Bogor proved successful in increasing the plant capacity from its original of 500 Lps to more than 1200 Lps. The performance of the WTP system was also significantly improved from poor performance to very good performance.

The investment cost for up-rating proved competitive when compared to alternatively constructing a new WTP system with an equivalent capacity and performance. Application of HR-WTP systems for the development of WTP system in Indonesia, i.e. rehabilitation, up-grading, and up-rating, as well as construction of a new WTP system, is expected to bring technical, financial, and economic benefits.

This new approach might be an innovative solution to the challenge of Millennium Development Goals in Water Supply Sector in Indonesia, where an additional capacity of ca 150,000 Lps should be developed within a 15 years period with an estimated budget of US \$1.5 billions. This budget might be reduced to less than $50 \%$ through the application of the HR-WTP system.
\end{abstract}

Keywords: loading rate, filtration rate, conventional system, high rate system

\section{Introduction}

There are operational problems of the water treatment plant (WTP) system in some cities in Indonesia (even though they are operated at low to medium loading rate) especially in the sedimentation units, e.g., sludge carry over, flow distribution, temperature effect, density flow, algal growth, scale deposits, wind effect, etc. (Mohajit, 2002). Due to these problems, the filter unit of the water treatment plant systems become inefficient because of its frequent clogging of the filter media.

If operational problems of the water treatment plant system can be solved and the loading rate of the system can also be increased then the systems will become more efficient and effective therefore the capacity of the water service may be increased and thus the demand of municipal drinking water might be supplied (Mohajit, 2010).

This paper will focus on the financial prospect to the application of the high rate water treatment plant (HR-WTP) system, where evaluation is based from the successful implementation of this system. 


\section{Material and Methods}

The HR-WTP system had been implemented successfully at Dekeng WTP system at PDAM Kota Bogor and Pedindang WTP system at PDAM Kota Pangkalpinang. The WTP systems were investigated and modified by introducing a new configuration of the systems to increase its capacity (up to double or even three fold) as well as to improve its performance. The detailed report of the successful application of HR-WTP system for Dekeng and Pedindang WTP system can be found elsewhere (Mohajit, 2010; 2006).

The implementation cost of the application of HR-WTP system and engineering cost estimate were then evaluated to compare with an equivalent capacity of building a new conventional WTP system. Financial analysis was then carried out to observe the bank-ability and feasibility as well as the prospect of the application and implementation of the High Rate Water Treatment Plant System.

Mathematical modelling for financial analysis was developed to simulate any conditional of the financial aspect in respect to the application and implementation of the HR-WTP system. Important parameter and criteria for the financial analysis in the model includes: Capacity of the WTP system (Lps), Unaccounted for Water (\%), Water Tariff (Rp/m3), Operation and Maintenance Cost (Rp/m3), Investment including VAT (value added tax, Rp.), IDC (interest rate during construction), Construction Periods (months), Tax, Interest Rate (\%), Conversion factor for HC (house connection), Equivalent HC vs System Capacity, Cost of HC, Targeted Period of Investment, Targeted IRR (internal rate of return), Inflation Rate/ Water Tariff Increase, Standby Cash for O \& M (operation and maintenance), Water Sales and Payment Efficiency, Maximum Extended Period of Payment, etc. The output of the financial analysis includes: BEP (break even point), IRR (internal rate of return), NPV (net present value), and DCR (debt coverage ratio).

\section{Result and Discussion}

The investment cost for the application of HR-WTP system proved competitive when compared to alternatively constructing a new WTP system with an equivalent capacity and performance. In the development of Dekeng WTP system it was estimated that constructing a new WTP system which includes additional supply for raw water resources would cost more than US \$ 7 millions, however by the application of HR-WTP system that investment cost had been reduced to less than US \$ 4 millions.

Financial analysis of the application of HR-WTP system in the development of Dekeng WTP system at PDAM Kota Bogor is depicted in Table 1. 
The financial analysis for the application of HR-WTP system is simulated under the following data and assumptions: Capacity of the WTP system is 700 Lps, Unaccounted for Water of $30 \%$, Water Tariff of Rp. 2500,-/m3, Operation and Maintenance Cost of Rp. 900,-/m3, Investment including VAT is Rp. 40.000.000.000,- Construction Periods of 12 months, Interest Rate of 19 \%, Conversion factor for House Connection is 7000 per year, Equivalent HC vs System Capacity is 70 HC per 1 Lps, The Cost of HC is Rp. 1.500.000,- Inflation Rate/Water Tariff Increase is 6\%, Standby Cash for O \& M of 3 months, Water Sales and Payment Efficiency of 97\%, Maximum Extended Period of Payment of 3 months, etc.

Table 1. Financial analysis for the application of HR-WTP system at PDAM Kota Bogor

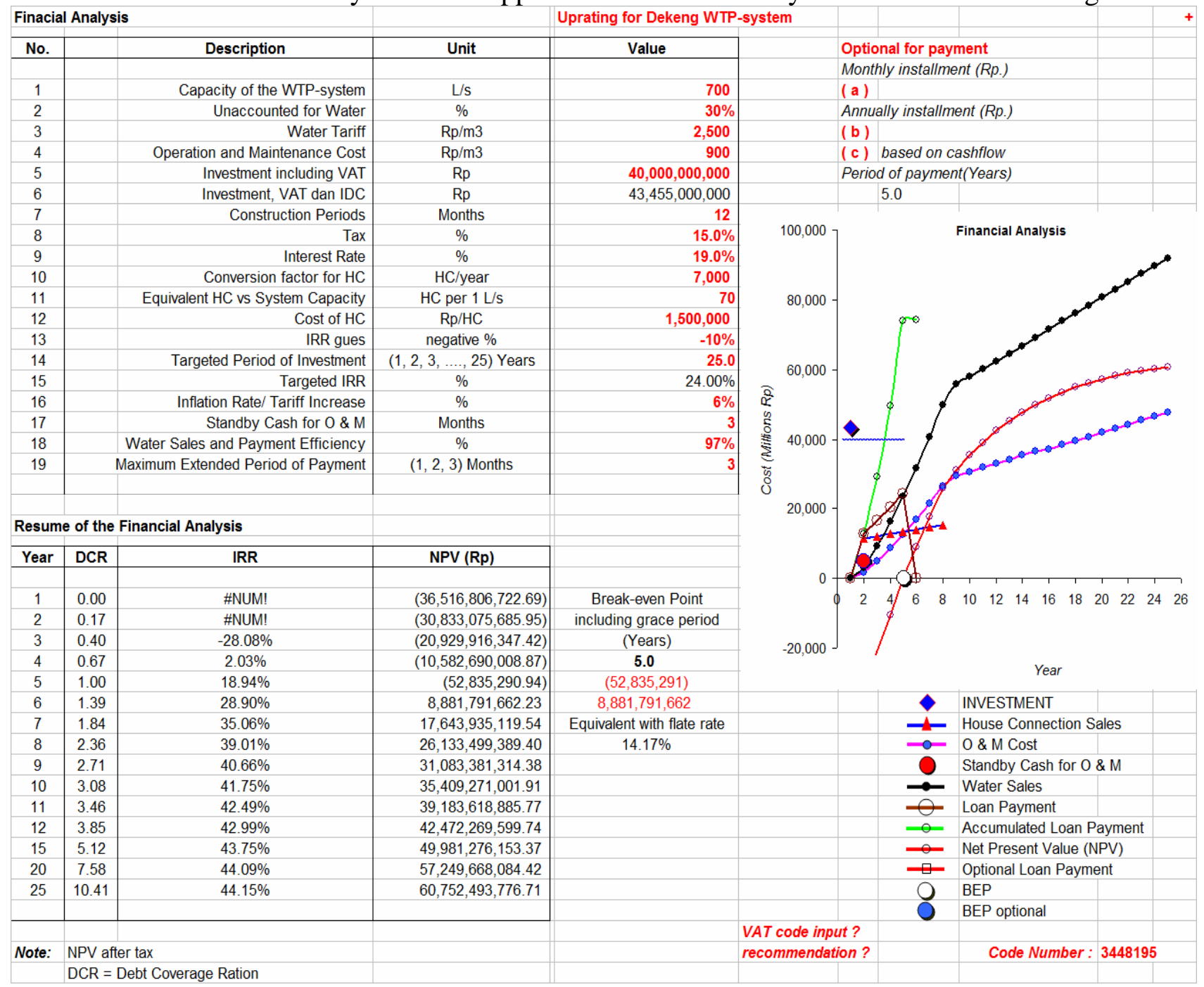

On the other hands the financial analysis for alternatively constructing a new WTP system is simulated under the following data and assumptions: Capacity of the WTP system is 500 Lps as proposed in master plan of WTP system, Unaccounted for Water of 30\%, Water Tariff of Rp. 2500,-/m3, Operation and Maintenance Cost of Rp. 900,-/m3, Investment including VAT is Rp. 
70.000.000.000,- Construction Periods of 12 months, Interest Rate of 19\%, Conversion factor for HC is 7000 per year, Equivalent HC vs System Capacity is 70 HC per 1 Lps, Cost of HC is Rp. 1.500.000,- Inflation Rate/Water Tariff Increase is 6\%, Standby Cash for O \& M of 3 months, Water Sales and Payment Efficiency of 97\%, Maximum Extended Period of Payment is 3 months, etc.

Comparison of the financial analysis for the application of the HR-WTP system versus constructing a new conventional WTP system can be seen as follows.

Table 2. Comparison of financial analysis for the application of HR-system versus conventional WTP system

\begin{tabular}{|c|l|c|c|}
\hline No. & Financial Parameter & HR-WTP system & Conventional System \\
\hline & & & \\
\hline 1. & Investment Cost & Rp. $40.000 .000 .000,-$ & $70.000 .000 .000,-$ \\
\hline 2. & Break Even Point & 5 years & 9.5 years \\
\hline 3. & IRR after 15 years & $43.75 \%$ & $23.66 \%$ \\
\hline 5. & NPV after 15 years & circa Rp. $50.000 .000 .000,-$ & ca Rp. $12.000 .000 .000,-$ \\
\hline 6. & Finankability & Bankable & less Bankable \\
\hline & & very attractive & far less attractive \\
\hline
\end{tabular}

\section{Conclussion}

The HR-WTP system, which is inexpensive, effective and efficient, has been developed to reduce the common operational problems, and also as an alternative for the development of water treatment plant systems capacity in Indonesia.

The investment cost for up-rating proved competitive when compared to alternatively constructing a new WTP system with an equivalent capacity and performance. Application of HR-WTP systems for the development of WTP system in Indonesia is technically implement-able and financially prospective which could bring socio economic benefits.

\section{Acknowledgement}

The author would like to thank to PDAM Kota Bogor and PDAM Kota Pangkapinang for their initiative effort and support in the application and implementation of HR-WTP system. Special correction and suggestion on this paper given by Professor EP Taiganides, $\mathrm{PhD}$ is also acknowledged with many thanks. 


\section{References}

Mohajit. (2002). Problems of water treatment in Indonesia due to extreme raw water quality fluctuations, in Seminar Proceedings: Irrigation Water Management in an Intercultural Context, A.H. Malik, P. Oberle and D. Prinz (Editors), Publisher: Institute of Water Resources Management, Hydraulic and Rural Engineering, University of Karlsruhe, Germany.

Mohajit. (2006). Innovative High Rate and High Performance Water Treatment Plant System, Option for Millennium Development Goals on Water Supply Sector, New Method, Competitive Investment Cost, Effective and Efficient for Operation/Maintenance; Humboldt International Conference on Biotechnology and Scientific Advances for Socio-economic Benefits; Penang Malaysia, Organized by University of Sciences Malaysia.

Mohajit. (2010). Successful experience in the application of high rate water treatment plant system, in Seminar Proceedings: The 1st International Conference on Sustainable Technology Development “Sustainable Technology Based on Environmental and Cultural Awareness", Organized by Udayana University of Indonesia in collaboration with Flensburg University of Germany, Denpasar Bali, 7-8 October 2010, pp C23-C32. 